FREIRE, S.M. et al. Avaliação das campanhas de vacinação anti-rábica de animais domésticos em Teresina-PI no período 2007/2008. PUBVET, Londrina, V. 4, N. 15, Ed. 120, Art. 810, 2010.

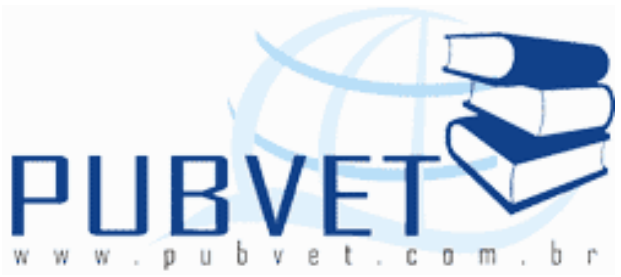

PUBVET, Publicações em Medicina Veterinária e Zootecnia.

\title{
Avaliação das campanhas de vacinação anti-rábica de animais domésticos em Teresina-PI no período 2007/2008
}

\author{
Simone Mousinho Freire $^{1}$, Keline Medeiros de Araújo $^{2}$, Mariane de Moraes \\ Costa $^{2}$, Ângela Piauilino Campos ${ }^{1}$, Fernando Luiz Lima de Oliveira ${ }^{3}$ \\ ${ }^{1}$ Mestranda em Ciência Animal. Universidade Federal do Piauí- UFPI \\ ${ }^{2}$ Graduanda em Ciências Biológicas - Universidade Estadual do Piauí- UESPI \\ ${ }^{3}$ Médico Veterinário. Doutorando em Ciência Animal- Universidade Federal do \\ Piauí- UFPI
}

\section{Resumo}

Avaliou-se a eficácia das campanhas de vacinação anti-rábica animal em Teresina-PI, no período 2007/2008, levando em consideração a cobertura vacinal e a estimativa da população canina e felina. $O$ perfil dessa população animal foi traçada a partir dos dados coletados nas citadas campanhas pela Gerência de Zoonoses e cedidos para o presente estudo. No ano de 2007 foram vacinados 119.459 animais (99,3\% da meta), e em 2008, 106.517 animais, o que corresponde a 92,2\% da meta estabelecida. Nas campanhas estudadas, a maioria dos animais vacinados foi da espécie canina, 74,66\% e $77,72 \%$ respectivamente, bem como do sexo masculino (59,05\% e $58,41 \%)$. Observou-se que, no período estudado, a população animal teve uma estimativa de crescimento de $0,02 \%$ apenas, o que superestima as coberturas vacinais. Com relação ao perfil dos animais, corroborou-se com estudos 
FREIRE, S.M. et al. Avaliação das campanhas de vacinação anti-rábica de animais domésticos em Teresina-PI no período 2007/2008. PUBVET, Londrina, V. 4, N. 15, Ed. 120, Art. 810, 2010.

anteriores, onde os cães machos são a preferência dos criadores de animais domésticos de estimação.

Palavras-chave: Raiva; cão; gato

\title{
Evaluation of the campaigns of rabies vaccination of domestic animals in Teresina-PI during 2007/2008
}

\begin{abstract}
We evaluated the effectiveness of vaccination campaigns against rabies in Teresina-PI, in the period 2007/2008, considering the vaccination coverage vaccine and the estimation of dog and cat population. The profile of the animal population was drawn from data collected in the preceding years by the Department of Zoonoses and transferred to the present study. In the year 2007 were vaccinated 119.459 animals (99.3\% of target), and in 2008, 106.517 animals, representing $92.2 \%$ of the goal. In the years studied, the majority of the vaccinated animals was of the canine species, $74.66 \%$ and $77.72 \%$ respectively, and male (59.05\% and $58.41 \%)$. It was observed that during the study period, the animal population had an estimated growth of $0.02 \%$ only, which overestimate the vaccination coverage. Regarding the profile of the animals, they agreed with previous studies, where male dogs are preferred by the breeders of domestic pets.
\end{abstract}

Keywords: Angry; dog; cat

\section{Introdução}

A raiva é uma encefalite viral aguda de mamíferos. É causada por um vírus da família Rhabdoviridae, gênero Lyssavirus que possui sete genótipos, sendo que somente o genótipo I (RABV) é encontrado nas américas. Este vírus é encontrado na saliva e nos tecidos nervosos dos animais infectados (RUPPRECHT, 2002; SCHEFFER , 2007; FRYMUS,2009). 
FREIRE, S.M. et al. Avaliação das campanhas de vacinação anti-rábica de animais domésticos em Teresina-PI no período 2007/2008. PUBVET, Londrina, V. 4, N. 15, Ed. 120, Art. 810, 2010.

Os reservatórios silvestres são morcegos, macacos e raposas e os domésticos são cães e gatos. A transmissão ocorre pela saliva de animais infectados. Os sinais mais comuns são: alterações de comportamento, agressão, dilatação da pupila, fotofobia, incoordenação motora, mordidas no ar, salivação excessiva, dificuldade para engolir e déficit múltiplos de nervos cranianos (BRASIL, 2005).

A organização mundial de saúde indica a vacinação em massa dos cães e gatos como sendo a principal estratégia de controle e eliminação da raiva nestes animais, uma vez que o contato direto com o homem no ambiente doméstico, aumenta a possibilidade de propagação da doença( WHO,2005).

No Brasil, o número de casos de raiva transmitidos por cães e gatos tem reduzido nos últimos seis anos, graças às campanhas de vacinação em massa. Do ano de 2003 a 2008, foram constatados 104 casos de raiva humana em treze estados da federação. A maioria dos casos (54\%) ocorreu na região nordeste. Em 2008, nesta região, ocorreu apenas um óbito por raiva humana, transmitida por primata não-humano, no estado do Ceará. No Piauí, desde 2002 não há relatos de morte causada pela raiva em humanos. Contudo, mesmo havendo uma tendência para o controle da raiva canina e felina, o risco de contrair a doença por outras espécies animais continua existindo (BRASIL,2008).

Este trabalho propõe avaliar a eficácia das campanhas de vacinação antirábica nos anos de 2007 e 2008 em Teresina-PI.

\section{Metodologia}

Este trabalho foi realizado no município de Teresina-PI que apresenta uma área territorial de $1.756 \mathrm{Km}^{2}$ e tem população canina e felina de aproximadamente 102.540 e 36.914 , respectivamente.

O controle da raiva urbana em Teresina é realizado pela Fundação Municipal de Saúde (FMS) através da Gerência de Controle de Zoonoses (GEZOON). 
FREIRE, S.M. et al. Avaliação das campanhas de vacinação anti-rábica de animais domésticos em Teresina-PI no período 2007/2008. PUBVET, Londrina, V. 4, N. 15, Ed. 120, Art. 810, 2010.

O trabalho trata-se de uma análise descritiva de dados das campanhas de vacinação anti-rábica em cães e gatos nos períodos de 2007 e 2008. Os dados foram obtidos através da análise de relatórios cedidos pelo Laboratório de Raiva da GEZOON - Gerência de Zoonoses de Teresina. Referem-se aos animais vacinados em pontos fixos da zona urbana do município de TeresinaPI.

Cães e gatos receberam uma dose fixa de $2 \mathrm{~mL}$ da vacina anti-rábica Fuenzalida modificada, sub-cutânea. A vacina foi produzida pelo Instituto de Tecnologia do Paraná (TECPAR) e a base de cálculo para cobertura vacinal baseia-se na relação entre a população humana e a população animal local , sendo que no caso de Teresina, a população animal (cães e gatos) corresponde em média $13 \%$ da população humana.

\section{Resultados e Discussão}

Em 2007, no município de Teresina-PI, a campanha anti-rábica desenvolveu-se, na zona urbana, em 310 postos de vacinação. Foram vacinados um total de 119.459 animais. Destes, 74,66 \% eram cães e 25,34 $\%$ gatos. Observou-se que a maioria dos cães vacinados eram machos (59,05 $\%$ ) e com faixa etária maior que cinco anos de idade (Tabela 1). A meta proposta neste mesmo ano foi de 89.729 cães e a campanha abrangeu um total de 89.182 correspondendo a 99,3\% de cobertura vacinal.

Dos 30.207 gatos vacinados em 2007, 61,17\% eram machos, e, devido à população ser menor que a de cães, não foi possível dividi-los por faixa etária.

No primeiro semestre de 2008, a campanha de vacinação anti-rábica na zona urbana de Teresina abrangeu 320 postos. Foram vacinados 106.517 animais, uma diminuição correspondente a $10,8 \%$ em relação ao ano anterior. Em 2008, o total de cães vacinados foi de 82.777, dos quais 58,4 \% eram machos. Observa-se uma preferência da população em criar animais machos, fato este que pode estar relacionado a problemas gerados eventualmente pelas 
FREIRE, S.M. et al. Avaliação das campanhas de vacinação anti-rábica de animais domésticos em Teresina-PI no período 2007/2008. PUBVET, Londrina, V. 4, N. 15, Ed. 120, Art. 810, 2010.

fêmeas como crias indesejadas e cios, que muitas vezes incomodam os proprietários (SOTO, 2006).

Tabela 1- Cães vacinados por faixa etária e sexo na zona urbana de Teresina, 2007

\begin{tabular}{ccccccc}
\hline & $<4 \mathrm{~m}$ & $4-11 \mathrm{~m}$ & $1-2 \mathrm{a}$ & $3-4 \mathrm{a}$ & $>5 \mathrm{a}$ & Total \\
\hline Macho & 4.414 & 8.473 & 13.063 & 11.659 & 15.057 & 52.666 \\
Fêmea & 3.312 & 6.067 & 9.644 & 7.610 & 9.883 & 36.516 \\
Total & 7.726 & 14.540 & 22.707 & 19.269 & 24.940 & 89.182
\end{tabular}

Fonte: GEZOON- Gerência de Zoonoses de Teresina (2007)

Legenda: $\mathrm{m}=$ meses e $\mathrm{a}=$ anos

A faixa etária mais atingida foi de animais mais velhos, acima de quatro anos de idade. (Tabela 2)

Tabela 2. Cães vacinados por faixa etária e sexo na zona urbana de Teresina, 2008

\begin{tabular}{lcccccc}
\hline & $<4 \mathrm{~m}$ & $4-11 \mathrm{~m}$ & $1-2 \mathrm{a}$ & $2-4 \mathrm{a}$ & $>4 \mathrm{a}$ & Total \\
\hline Macho & 3.673 & 7.818 & 12.473 & 10.884 & 13.499 & 48.347 \\
Fêmea & 2.922 & 5.812 & 8.949 & 7.307 & 9.440 & 34.430 \\
Total & 6.595 & 13.630 & 21.422 & 18.191 & 22.939 & 82.777
\end{tabular}

Fonte: GEZOON- Gerência de Zoonoses de Teresina (2008)

Legenda: $\mathrm{m}=$ meses e $\mathrm{a}=$ anos

A meta estabelecida para a campanha de vacinação em 2008 foi de 89.743 cães e a cobertura realizada totalizou $92,2 \%$, um pouco menor que a do ano anterior. Tal fato pode estar relacionado à pouca divulgação para a população.

O total de gatos vacinados em 2008 foi de 23.740 animais, sendo sua maioria, 60,77\%, de machos. 
FREIRE, S.M. et al. Avaliação das campanhas de vacinação anti-rábica de animais domésticos em Teresina-PI no período 2007/2008. PUBVET, Londrina, V. 4, N. 15, Ed. 120, Art. 810, 2010.

No município de Teresina, Estado do Piauí, a Gerência de Zoonoses manteve por dois anos consecutivos uma cobertura vacinal superior a $90 \%$, satisfazendo, portanto, a meta proposta por Coleman \& Dye (1996) e Hildebrand et al.(2008) no qual, uma cobertura em torno de $70 \%$, evitaria uma epidemia de raiva em $96,5 \%$ dos casos.

No que tange à taxa de crescimento populacional canino, os dados são questionáveis, pois, com base nas metas estabelecidas para os anos de 2007 e 2008, houve uma estimativa de crescimento de apenas 14 cães, um aumento de apenas 0,02 \% aproximadamente. No entanto, a taxa de crescimento populacional canino varia em média de $15 \%$. Isto pode ser verificado em trabalhos realizados por Soto (2006), no município de Itabuna-SP, onde o percentual de crescimento canino foi de $16 \%$ e por Andrade (2008), no município de Araçatuba-SP, no qual a população de cães com até um ano de idade que representava $20,2 \%$ dos animais de 1994 , passou a 32,5\% em 2004. Nota-se ainda que nesses municípios a maior relação populacional homem/cão encontrada foi de 7:1 e em Teresina-PI, esta relação varia em média de 8: 1, pois temos mais de 100.000 cães e 800.000 habitantes.

Tal fato reforça ainda mais a nossa suspeita de que a estimativa do aumento da população canina usada para as campanhas está muito aquém da realidade.

\section{Referências Bibliográficas}

1 Andrade AM. et al. Estudo descritivo da estrutura populacional canina da área urbana de Araçatuba, São Paulo,Brasil, no período de 1994 a 2004. Cad. Saúde Pública, Rio de Janeiro, 2008; 24:927-932.

2 BRASIL. Ministério da Saúde. Aspectos epidemiológicos da Raiva. Brasília, DF, 2008. Disponível em: < http://portal.saude.gov.br/portal/saude/visualizar_texto.cfm?idtxt=27598>. Acesso em: 19 jun.2009.

3 BRASIL. Ministério da Saúde. Secretaria de vigilância em saúde. Guia de vigilância epidemiológica: série A. Normas e manuais técnicos. 6. ed. Brasília, DF, 2005. 32p. Disponível em: <http://portal.saude.gov.br/portal/arquivos/pdf/raiva_gve.pdf>. Acesso em: 18 jun. 2009.

4 Coleman PG.; Dye C. Immunization coverage required to prevent outbreaks of dog 
FREIRE, S.M. et al. Avaliação das campanhas de vacinação anti-rábica de animais domésticos em Teresina-PI no período 2007/2008. PUBVET, Londrina, V. 4, N. 15, Ed. 120, Art. 810, 2010.

rabies. Vaccine, 1996; 14:185-186.

$5 \quad$ Frymus $T$. et al . Feline Rabies: $A B C D$ guidelines on prevention and management. J Feline Med Surg, 2009; 11:585-593.

6 Hildebrand $\mathrm{JH}$ de. et al., Uso de sistemas de informação geográfica em campanhas de vacinação contra a raiva. Rev. Saúde Pública. São Paulo, 2008; 42:1005-1011.

$7 \quad$ Rupprecht CE.et al. Rabies re-examined. Lancet infect Dis. 2002; 2:327-343.

8 Soto FRM. et al. Dinâmica populacional canina no município de Itabuna-MG: estudo retrospectivo. Braz. J. Vet. Res. anim. Sci. São Paulo, 2006; 43:178-185.

9. Scheffer KC et al. Vírus da raiva em quirópteros naturalmente infectados no Estado de São Paulo, Brasil. Revista de Saúde Pública 3:389-395, 2007.

10. World Health Organization (WHO). WHO expert consultation on Rabies.TRS 931 Genebra. 2005. Disponível em: <http://www.who.int/rabies/animal/ExcerptTRS931.pdf> Acesso em: 09 mar. 2010. 